\title{
Correction
}

\section{Correction: Novel Gut-Based Pharmacology of Metformin in Patients with Type 2 Diabetes Mellitus}

\section{The PLOS ONE Staff}

Figure 2 was incorrectly published as a duplicate of Figure 3.

Please see the corrected Figure 2 here.

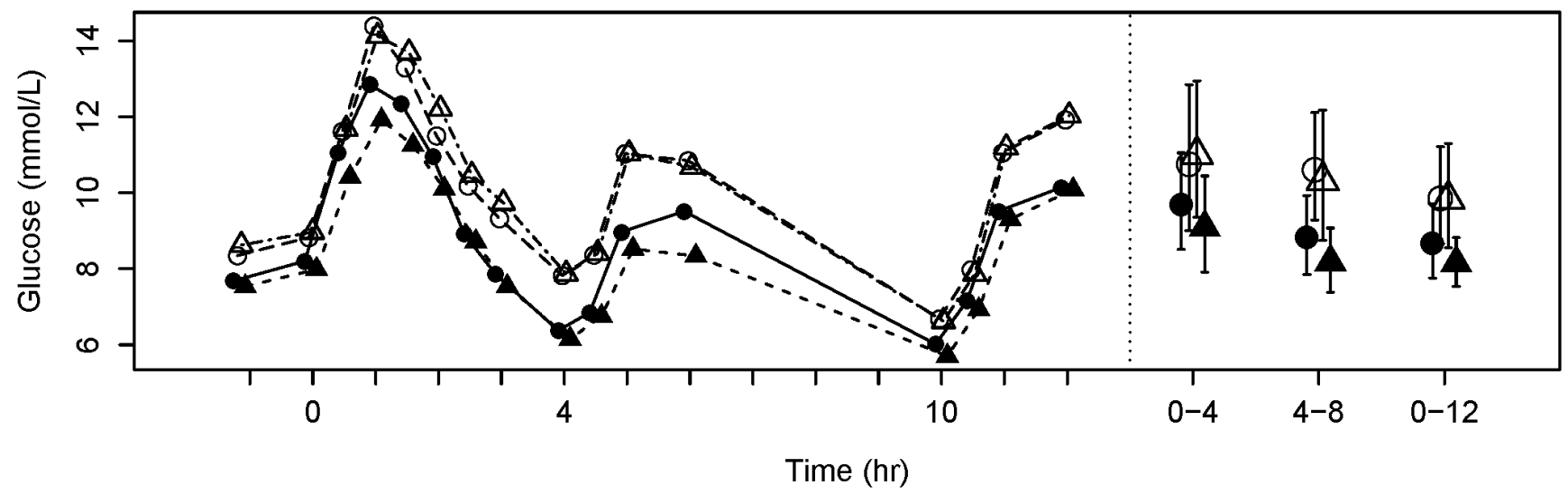

Figure 2. Postprandial glucose profiles. Mean plasma glucose profiles during the postprandial period of the day (left) and weighted mean AUC ( $\pm 95 \%$ confidence interval) over $0-4,4-8$ and $0-12 \mathrm{~h}$ (right). Data points are coded for visit number where: black circles $=$ Visit $1 ;$ white circles $=$ Visit 2; white triangles $=$ Visit 3; black triangles $=$ Visit 4 . doi:10.1371/journal.pone.0100778.g002

\section{Reference}

1. Napolitano A, Miller S, Nicholls AW, Baker D, Van Horn S, et al. (2014) Novel Gut-Based Pharmacology of Metformin in Patients with Type 2 Diabetes Mellitus. PLoS ONE 9(7): e100778. doi:10.1371/journal.pone.0100778

Citation: The PLOS ONE Staff (2014) Correction: Novel Gut-Based Pharmacology of Metformin in Patients with Type 2 Diabetes Mellitus. PLoS ONE 9(8): e106594. doi:10.1371/journal.pone.0106594

Published August 25, 2014

ing the postprandial period of the day (left) and weighted mean AUC distributed under the terms of the Creative Commons Attribution License, which permits unrestricted use, distribution, and reproduction in any medium, provided the original author and source are credited. 